\title{
Sources of public response to the death penalty in Britain, 1930-65
}

\section{Lizzie Seal (Senior Lecturer in Criminology at University of Sussex)}

Abstract: This article is adapted from a presentation given at Sources and Methods in Criminology and Criminal Justice, a workshop on sources and methods in socio-legal research held at the Institute of Advanced Legal Studies in November 2015. It explores the selection of qualitative sources for a project that aimed to uncover public responses to capital punishment in the mid twentieth-century. I discuss which sources were selected and consider their strengths and weaknesses. I conclude that the particular sources chosen as data can, in themselves, help to shape researchers' thinking about their findings.

Keywords: public response; historical sources; death penalty; capital punishment

\section{Introduction}

Capital punishment is an emotive and divisive topic. As a form of punishment, it is also heavily symbolic, communicating messages and meanings about the exercise of authority and the limits of acceptable behaviour. ${ }^{1}$ It also conveys less obvious social and cultural meanings related to the construction of racial and gendered identities, ${ }^{2}$ and the boundaries of the imagined national community. ${ }^{3}$

Britain retained the death penalty until 1965 and carried out executions until 1964. The research discussed in this article focused on public responses to capital punishment in the era of abolition from 1930 onwards - when the abolitionist campaign strengthened and there were legislative attempts to end the death penalty. ${ }^{4}$ While scholars have explored the political and legislative context of abolition, the starting point for the project was the almost complete lack of attention to capital punishment's wider cultural place during this era. It sought to address important questions such as: How did the public react to the death penalty and what shaped these reactions? What kind of cultural meanings became attached to capital cases? How did reactions vary according to the details of specific cases, such as the identities of the perpetrator and victim? How did the public feel about death as a form of punishment?

Researching historical public views poses methodological challenges, particularly if the aim is to unearth qualitative insights. Opinion polls on the death penalty in Britain were conducted from the 1930s onwards. These are useful in terms of providing an overview of how people responded to the issue, and are a good guide to how people thought about it in the abstract. More recent survey research on public views on capital punishment finds that both suggesting an alternative punishment, such as the whole life sentence, and giving more information on significant details such 
as mitigating factors, lead to a decrease in approval for the death penalty. ${ }^{5}$ Therefore, broad brush opinion polls do not reveal the nuances and complexities of people's views and feelings. Polls force respondents to choose an answer to a question, but this does not capture the contingent, shifting and possibly contradictory nature of their views.

\section{Choosing sources}

For my own part, I also wanted to know how people responded to actual cases as historical events, rather than simply how they understood capital punishment in the abstract. I wanted to unlock the emotional and context specific aspects of public response. With these aspirations to guide me, I chose sources that would offer rich, qualitative data. The primary source was letters sent by members of the public to successive Home Secretaries concerning particular cases. The decision about whether to reprieve a convicted murderer was the Home Secretary's alone (although he received recommendations from civil servants). The letters can be found in capital case files in The National Archives. Largely, they can be understood as belonging to the longstanding tradition of petitioning for mercy - making representation on behalf of the condemned with the hope of securing reprieve. However, following the Second World War when capital punishment became a more high profile and contested issue than it had been earlier in the century, there were also letter writers who argued against granting a reprieve.

I selected cases according to the volume of letters received, but also with regard to when they occurred. Prior to the war, a large number of letters in a file was around thirty. After the war, and particularly from the late 1940s, some cases attracted hundreds of letters. This selection process meant that my sample contained many high profile cases, which were well publicised and culturally contested. As such, they were invaluable sources of the kinds of meaning related to capital punishment that I wished to uncover. In order to establish manageable limits for the project, I selected 25 cases from the period. Additionally, I included letters sent in response to pieces of abolitionist legislation, which were held in Home Office files. Altogether, this garnered around 3000 letters.

Another source for qualitative opinion on capital punishment is the Mass Observation Capital Punishment survey, carried out in 1948 and 1955-6. Mass Observation was established in 1937 as a social research organisation, with a mission to investigate the 'ordinary' and the 'everyday'. ${ }^{6}$ It sought to understand public feeling and the relationship between feelings and opinions. ${ }^{7}$ The capital punishment surveys were commissioned by the Daily Telegraph and coincided with government proposals to suspend the death penalty for a period of time. Both contained an open ended question asking respondents how they felt about the suspension of capital punishment. The mid- 
1950s survey also contained a question on whether there was anything the respondents had 'seen, heard or read' that influenced their views on the death penalty. ${ }^{8}$ This question produced especially useful responses for my research as people mentioned particular cases, or types of case, that shaped their views on the death penalty.

Given that the project aimed to uncover how people felt about actual cases and the death penalty as it was carried out in practice, oral history offered another potential source of reflective and personally situated data. The Millennium Memory Bank, held in the British Library Sound Archive, contains recordings of oral history interviews conducted for the BBC's 'A Century Speaks' radio series, which was broadcast in $1999 .{ }^{9}$ The interviews were intended to provide a 'snapshot' of Britain at the end of the twentieth century. They invited participants to reflect on change in their communities across sixteen possible topics. One of these was crime and law, in relation to which interviewees were asked how attitudes towards and experiences of crime had changed within their living memory. This topic meant that some participants spoke about capital punishment.

The letters, Mass Observation responses and oral history interviews were the diverse sources that, for my project, constituted data on public responses to capital punishment in mid twentieth-century Britain. In order to help contextualise the views that people expressed, it was necessary to pay attention to newspaper reports on capital cases and the issue of the death penalty more widely. News stories and features are not forms of public opinion in themselves, but they were the means through which 'ordinary' people could learn about capital punishment. In the mid twentieth-century, newspaper readership was extremely high. ${ }^{10}$ People's understanding of particular cases and of the wider abolition debate was mediated by the press and, particularly from the late 1940s, the death penalty received a great deal of media attention. The totality of press coverage is vast and was beyond the scope of my project. I performed searches of the electronic archives of national newspapers, The Times, The Guardian, Daily Mirror, Daily Express and Daily Mail. The capital case files contained quite a few news clippings, which provided a wider range of coverage in relation to these particular cases.

\section{Strengths and Weaknesses}

Qualitative responses to capital punishment have the important strength of complicating our understanding of public views. They make it possible to analyse the symbolic meanings people attached to capital punishment. The main source, letters to Home Secretaries, are responses articulated on their authors' own terms and in their own choice of language. They were written as the cases were unfolding and as legislative changes were being made. They are not hypothetical or speculative, and they have not been engineered by a researcher. They are incredibly rich and also 
extremely varied. They run the gamut from the highly formal to the intensely personal. Letters can be understood as a 'mixed genre'. ${ }^{11}$ Some authors, despite not being personally acquainted with the condemned, personally identified with them. They included fragments of autobiography in making their pleas for mercy - and their pleas for punishment. In this sense, the letters are more than simply sources of public opinion on the death penalty but also reveal aspects of mid twentieth-century selfhood and the expression of emotion.

There are caveats to bear in mind when analysing these letters as public response. In their motivation to write to the Home Secretary about a capital case or some legislation going through Parliament, the letter writers were unusual. They were probably more intensely concerned about the death penalty as an issue or the individual cases than the vast majority of people. Counting their letters as forms of 'public response' suggests that there is something typical about these responses but sending the letters was not typical. This potential problem was somewhat mitigated by comparison with the Mass Observation surveys. Mass Observation used stratified sampling to question around 6000 people for each survey. ${ }^{12}$ These respondents were therefore not unusually motivated to consider the death penalty. In comparison with the letters, the answers to the open ended questions are shorter and do not have the same depth. However, in terms of common themes and meanings attached to capital punishment and to certain cases, they are similar.

I found this unsurprising. Although the letter writers were unusual in one sense, in others they were not. They were ordinary citizens articulating concerns about particular cases or the death penalty as a form of punishment that were prevalent in contemporary popular discourse. This was where attention to press coverage helped to contextualise the responses. I do not mean that individuals simply parroted what they head read in the newspaper but that their views and perceptions were inevitably shaped by the contemporary cultural and political background. The letters disproportionately represent abolitionist views, or concerns about flaws in the death penalty. This would be a problem if the purpose of the study was to measure opinion but sensitivity to the intended purpose of the letters means that this can be taken into account. Some authors expressed doubts about capital punishment in relation to particular cases, while asserting that they did not disagree with it in principle. It is exactly this kind of complexity, which can be missed in straightforward opinion polling, that these sources can reveal.

One drawback of the letters is that the demographic profile of the author is not necessarily provided. There are quite a few anonymous letters, meaning that the gender and location of the writer cannot be known. The majority did sign their letters and included their addresses, but many only gave an initial rather than their whole name. Some signatures are illegible. Other pertinent details, such as 
the author's age, profession or social class, could only be gleaned if they made reference to it, which they usually had no cause to do. The significance of these demographic factors could, for the most part, not be analysed. There were certain exceptions. For example, the case that attracted the highest number of letters (around 600) was that of Ruth Ellis in 1955, the last woman to be hanged in Britain. Ellis shot her lover, David Blakely, who had both physically and emotionally abused her. Many female correspondents either personally identified with Ruth Ellis's experiences, or felt that she had been unfairly treated based on her womanhood. ${ }^{13}$

Letters sent to Home Secretaries perhaps disproportionately represent educated, middle class voices. As discussed, the authors' social class background remains largely unknown. However, the letter is a relatively democratic form. ${ }^{14}$ It is cheap to write and send, and only requires a basic rather than high level of literacy. By no means all of the letters exhibited high levels of literacy, indicating that there was some diversity of authorship in terms of education level and, by association, social class.

\section{Challenges}

By far the greatest challenge that I encountered in relation to the sources was analysis of the oral history interviews. Whereas the letters and survey responses were all from the mid twentiethcentury and shared common themes, the interviews were very different. My assumption when including them in the project was that they would contain people's reflections and memories of the significance of particular cases. This was true for some respondents who had worked in the criminal justice system. However, listening to the recordings revealed that, where interviewees expressed opinions about the death penalty, it was usually in relation to the present day (the late 1990s). For example, in considering how their communities had changed, they discussed whether they thought the death penalty should be reintroduced. I concluded that the oral histories could not be understood as sources of public response to capital punishment in the mid twentieth-century. However, the interviews do reveal how capital punishment has continued to figure as a symbol of social order and how collective memories of miscarriages of justice inform anti-death penalty views. ${ }^{15}$ They are valuable sources of data but do not tell us about the mid twentieth century.

\section{Conclusion}

These sources enabled me to take a fresh approach to researching capital punishment in mid twentieth-century Britain. They made it possible to analyse the expressive role of the death penalty - the diverse meanings that it had for ordinary people and their role in endowing it with meaning. In addition to shedding new light on cultural understandings of capital punishment, an unorthodox collection of sources expands the boundaries of research on public response. When the topic is 
historical, there frequently is not a straightforward way of discovering how people thought and felt about something. It is necessary to think creatively about which sources can be used and to place them within their historical context.

The sources that we use for our research can, in themselves, help to shape our thinking. For this project, I wanted to investigate public attitudes and responses. However, the sometimes personal nature of individuals' responses, or the passion with which they expressed their attitudes, made me realise that the project was also about 'public feeling'.$^{16} \mathrm{I}$ had researched the history of the death penalty but I had also researched the history of how people in Britain articulated emotion in relation to public events.

\footnotetext{
${ }^{1}$ Christian Boulanger and Austin Sarat, 'Putting Culture into the Picture', A Sarat and C Boulanger, The Cultural Lives of Capital Punishment, Stanford, Stanford University Press, 2005, pp. 1-9.

${ }^{2}$ See for example Carolyn Strange, 'Masculinities, Intimate Femicide and the Death Penalty in Australia, 18901920' British Journal of Criminology, 2003, 43, 2, 310-339 and Benjamin Fleury-Steiner, 'Death in "Whiteface"', C J Ogletree Jr and A Sarat (eds.), From Lynch Mobs to the Killing State, New York, New York University Press, 2006.

${ }^{3}$ Lizzie Seal, 'Imagined Communities and the Death Penalty in Britain, 1930-65', British Journal of Criminology, 2014, 54, 5, 908-27.

${ }^{4}$ See Lizzie Seal, Capital Punishment in Twentieth-Century Britain: Audience, Memory, Justice, London, Routledge, 2014, pp. 21-7.

${ }^{5}$ Roger Hood and Florence Seemungal, 'Public Opinion on the Mandatory Death Penalty in Trinidad', A Report to the Death Penalty Project and the Rights Advocacy Project of the University of West Indies Faculty of Law, 2011: http://www.deathpenaltyproject.org/wp-content/uploads/2012/12/Public-Opinion-on-the-MandatoryDeath-Penalty-in-Trinidad-Report-Final.pdf and Kyle A Burgason and Lynn Pazzani, 'The Death Penalty: A Multilevel Analysis of Public Opinion', American Journal of Criminal Justice, 2014, 39, 4, 818-38.

${ }^{6}$ 'History of Mass Observation', Mass Observation: http://www.massobs.org.uk/about/history-of-mo

${ }^{7}$ Claire Langhamer, "'The Live Dynamic Whole of Feeling and Behaivor": Capital Punishment and the Politics of Emotion, 1945-157', The Journal of British Studies, 2012, 51, 2, 416-41, p. 418.

${ }^{8}$ Report on Survey, Correspondence 1956, Capital Punishment Survey 1955-6, MOA-72-2-A.

9 'Listen to the Century Speak', BBC News, 17.5.00: http://news.bbc.co.uk/1/hi/uk/752209.stm

${ }^{10}$ See Adrian Bingham, Family Newspapers? Sex, Private Life, and the British Popular Press, 1918-1978, Oxford, Oxford University Press, 2009, pp. 16-18.

${ }^{11}$ Natalie Zemon Davis, Fiction in the Archives: Pardon Tales and their Tellers in Sixteenth-Century France, Stanford, Stanford University Press, 1987, p. 5.

${ }^{12}$ Langhamer, 'The Live Dynamic', pp. 425-6.

${ }^{13}$ Lizzie Seal, 'Ruth Ellis and Public Contestation of the Death Penalty', The Howard Journal, 2011, 50, 5, 492504.

${ }^{14}$ Caroline Franklin, 'Introduction: The Material Culture of Eighteenth-Century Women's Writing', Women's Writing, 2014, 21, 3, 285-89, p. 287.

${ }^{15}$ Seal, Capital Punishment, pp. 167-81.

${ }^{16}$ See Erika Doss, Memorial Mania: Public Feeling in America, Chicago, University of Chicago Press, 2012.
}

Biography: Lizzie Seal is Senior Lecturer in Criminology at University of Sussex. Her research interests are in the areas of historical, cultural and feminist criminology. She has published three monographs: Women, Murder and Femininity: Gender representations of women who kill (Palgrave, 2010), (with Maggie O'Neill) Transgressive Imaginations: Crime, Deviance and Culture (Palgrave, 2012) and Capital Punishment in Twentieth-Century Britain: Audience, Justice, Memory (Routledge, 2014). 